\title{
Recombinant human interleukin receptor antagonist influences serum chemokines in patients with rheumatoid arthritis
}

\author{
JUN BAO $O^{I, 2}$, WEI LIU ${ }^{2}, Y I-X I A O B A O^{I}$ \\ ${ }^{1}$ Department of Paediatrics, Xinhua Hospital, Shanghai Jiaotong University School of Medicine, Shanghai, PR China \\ ${ }^{2}$ Department of Rheumatology and Immunology, Shanghai Changzheng Hospital, Second Military Medical University, Shanghai, PR China
}

\begin{abstract}
Objective: To investigate the serum expressions of chemokines CCL2 and CCL3 in patients with rheumatoid arthritis $(R A)$ who were treated with recombinant human interleukin 1 (IL-1) receptor antagonist $(I L-1 R a)$.

Material and methods: Serum CCL2 and CCL3 were determined using an enzyme-linked immunosorbent assay in 54 active RA patients before and after treatment with IL-1Ra or a placebo, as well as 36 healthy controls.

Results: Compared with the healthy controls, all the 54 RA patients exhibited higher serum CCL2 and CCL3 before and after treatment $(p<0.05)$. However, patients who had a good response to IL-IRa treatment had significantly lower mean changes in the serum CCL2 and CCL3 levels from baseline to the last injection than IL-1Ra non-responders $(p<0.01)$.

Conclusions: CCL2 and CCL3 may be useful efficacy markers of IL-1Ra treatment.
\end{abstract}

Key words: arthritis, rheumatoid, chemokines, interleukin-1 receptor antagonist protein, drug therapy.

(Centr Eur J Immunol 2014; 39 (2): 170-173)

\section{Introduction}

Rheumatoid arthritis (RA) is characterised by chronic inflammation of the synovial membrane, which causes progressive joint damage and increased disability. The inflammatory process involves the migration and infiltration of peripheral blood inflammatory cell leukocytes into the synovial tissue. These cells, including lymphocytes, neutrophils and monocytes, produce a variety of inflammatory mediators, including cytokines, chemokines and matrix-degrading enzymes [1]. The inhibition of pro-inflammatory cytokines can reduce the manifestations of RA, improve function and retard radiological evidence of joint damage. This discovery has led to the development of new therapies, including recombinant human interleukin-1 receptor antagonist (IL-1Ra) [2, 3].

Chemokines are cytokines that exert chemotactic activity towards lymphocytes, neutrophils and monocytes, and they play a crucial role in the migration and recruitment of inflammatory cells into the synovium. Elevated levels of CC chemokine ligands CCL2 (monocyte chemoattractant protein-1 - MCP-1), CCL3 (macrophage inflammatory protein-1 $\alpha-$ MIP-1 $\alpha$ ), CCL5 (regulated and normal T cell expressed and secreted - RANTES) and CCL20 (MIP-3 $\alpha$ ) have been found in the serum and synovial fluid of RA patients $[4,5]$. Patients with early RA had elevated expression levels of synovial fluid CCL2 and CCL3, which were positively correlated with macrophage infiltration into the synovium, suggesting that CCL2 and CCL3 may function as predictable factors of RA synovitis and treatment efficacy $[6,7]$. However, to date, only limited studies have been available.

In this study, we investigated the relationship of serum CCL2 and CCL3 concentrations with clinical outcomes in RA patients who were treated with IL-1Ra.

\section{Material and methods}

\section{Study protocol}

A total of 54 active RA patients and 36 healthy controls were enrolled into the study, which was conducted at the Shanghai Changzheng Hospital in China from September 2009 to October 2011. Eligible RA patients were 18-79 years of age, fulfilled the revised 1987 American Rheumatism Association criteria for the classification of RA and had received methotrexate (MTX) treatment for at least 12 weeks before enrolment. Active RA was defined as four or 
more swollen joints, six or more tender joints and at least one of the following: a serum C-reactive protein (CRP) level of at least $10 \mathrm{mg} / \mathrm{l}$, an erythrocyte sedimentation rate (ESR) of at least $28 \mathrm{~mm} /$ hour or morning stiffness that lasted longer than 45 minutes.

All the RA patients were double-blindly randomised to receive daily subcutaneous injections of IL-1Ra (80 $\mathrm{mg}$ ) or a placebo with concurrent MTX therapy for 24 weeks, which was reported in our previous paper [8]. Of the 42 IL-1Ra-treated patients, 27 were assigned as responders who exhibited at least $20 \%$ improvement according to the criteria of the American College of Rheumatology (ACR20) [9] after 24 weeks of treatment, whereas the other 15 patients were non-responders who did not achieve an ACR20 response or withdrew before the end of the study.

The clinical activity of RA was assessed using the Modified Disease Activity Score in 28 joints (DAS28) [10]. Fasting sera were collected at baseline and after the last injection from the enrolled RA patients and healthy controls. The serum levels of CCL2 and CCL3 were determined using enzyme-linked immunosorbent assay (ELISA) kits (R\&D Systems, Wiesbaden-Nordenstadt, Germany). The sensitivities of the ELISA kits were $5 \mathrm{pg} / \mathrm{ml}$ (CCL2) and $10 \mathrm{pg} / \mathrm{ml}$ (CCL3).

All of the patients provided written informed consent. The study protocol was approved by the institutional review committee and was conducted according to the Declaration of Helsinki and all subsequent revisions.

\section{Statistical analysis}

The continuous variables and the DAS28 were analysed using Student's paired $t$-test, an analysis of variance (parametric) or Wilcoxon's rank-sum test (nonparametric) when appropriate. The correlation between the serum chemokines and the DAS28 was determined using Spearman's rank-order test. Two-tailed $p$ values of 0.05 or less were considered statistically significant.

\section{Results}

\section{Patient characteristics}

A total of 54 RA patients and 36 healthy controls were recruited into the study. The IL-1Ra $(n=42)$ and placebo $(n=12)$ groups were well-balanced according to their demographic and baseline characteristics (Table 1). Of the 36 healthy controls who were $24-79(52.2 \pm 14.70)$ years of age, 9 were males and 27 females.

\section{Serum CCL2 and IL-1Ra treatment}

In the 54 RA patients who were treated with IL-1Ra or a placebo, the serum CCL2 levels before and after treatment were both significantly higher than those of the healthy controls $(p<0.001)$. There were no significant differences in the serum CCL2 levels and the mean CCL2 changes from baseline between the two treatment groups $(p>0.05$, Table 2).

An additional comparison was conducted in the responders to IL-1 Ra $(n=27)$ and the non-responders to IL-1Ra $(n=15)$ vs. placebo. The serum CCL2 concentrations before and after treatment in both the responders and non-responders were significantly higher than those in the healthy controls $(p<0.001)$. There were no significant differences in the serum CCL2 concentrations and the mean CCL2 changes between the IL-1Ra responders, non-responders and the placebo group $(p>0.05)$. However, the serum CCL2 concentrations in the IL-1Ra responders declined following IL-1Ra treatment, and the responders had a higher mean CCL2 change from baseline to the last injection than the IL-1Ra non-responders $(p<0.01$, Fig. 1).

Table 1. Characteristics of the 54 rheumatoid arthritis patients treated with IL-1Ra or placebo at baseline

\begin{tabular}{|c|c|c|}
\hline & $\begin{array}{l}\text { IL-1Ra } \\
(n=42)\end{array}$ & $\begin{array}{l}\text { Placebo } \\
(n=12)\end{array}$ \\
\hline Age (years) & $45 \pm 10$ & $45 \pm 11$ \\
\hline Sex, female $(\%)$ & $33(79)$ & $10(83)$ \\
\hline Weight (kg) & $59 \pm 10$ & $54 \pm 9$ \\
\hline RF positivity (\%) & $32(76)$ & $10(83)$ \\
\hline ANA positivity (\%) & $14(33)$ & $5(42)$ \\
\hline Corticosteroid use (\%) & $16(38)$ & $7(58)$ \\
\hline MTX dose (mg/week) & $10.3 \pm 1.8$ & $11.3 \pm 2.7$ \\
\hline Swollen joint count $(0-66)$ & $7.8 \pm 4.5$ & $6.1 \pm 4.0$ \\
\hline Tender or painful joint count (0-68) & $11.4 \pm 6.5$ & $10.4 \pm 7.1$ \\
\hline $\begin{array}{l}\text { Physician's assessment of disease } \\
\text { activity }(0-100 \mathrm{~mm})\end{array}$ & $51 \pm 20$ & $52 \pm 16$ \\
\hline $\begin{array}{l}\text { Patient's assessment of disease activity } \\
(0-100 \mathrm{~mm})\end{array}$ & $57 \pm 20$ & $57.4 \pm 19.0$ \\
\hline Patient's assessment of pain $(0-100 \mathrm{~mm})$ & $51 \pm 21$ & $47 \pm 17$ \\
\hline HAQ score $(0-3)$ & $0.6 \pm 0.7$ & $0.7 \pm 0.6$ \\
\hline $\mathrm{CRP}(\mathrm{mg} / \mathrm{l})$ & $19 \pm 19$ & $13.4 \pm 13.7$ \\
\hline $\mathrm{ESR}(\mathrm{mm} / \mathrm{hr})$ & $35 \pm 24$ & $33 \pm 24$ \\
\hline Duration of morning stiffness (min/day) & $82 \pm 90$ & $66 \pm 99$ \\
\hline DAS28 & $5.5 \pm 1.3$ & $5.2 \pm 1.0$ \\
\hline
\end{tabular}

These data are the mean \pm SD or the number (\%) unless indicated otherwise. There were no significant differences between the groups according to these characteristics.

$I L-1 R a-I L-1$ receptor antagonist; $R F$ - rheumatoid factor; $A N A$ - antinuclear antibodies; MTX - methotrexate; HAQ - health assessment questionnaire; CRP $-C$-reactive protein (normal $<10 \mathrm{mg} / \mathrm{l}$ ); ESR - erythrocyte sedimentation rate; DAS 28 - disease activity score in 28 joints 
Table 2. Serum CCL2 concentrations before and after treatment

\begin{tabular}{|c|c|c|c|}
\hline & Before treatment & After treatment & Mean changes \\
\hline IL-1Ra group & $820.0 \pm 767.8^{* * *}$ & $803.4 \pm 857.5^{* * *}$ & $9.82 \pm 8.32$ \\
\hline IL-1Ra responders & $944.1 \pm 801.1 * * *$ & $618.2 \pm 778.7 * * *$ & $-550.6 \pm 679.7^{s}$ \\
\hline IL-1Ra non-responders & $654.7 \pm 733.2 * * *$ & $844.2 \pm 620.0 * * *$ & $566.8 \pm 729.2$ \\
\hline Placebo group & $920.9 \pm 759.8^{* * *}$ & $837.5 \pm 736.3^{* * *}$ & $71.72 \pm 866.1$ \\
\hline Healthy controls & \multicolumn{2}{|c|}{$32.54 \pm 15.4$} & - \\
\hline
\end{tabular}

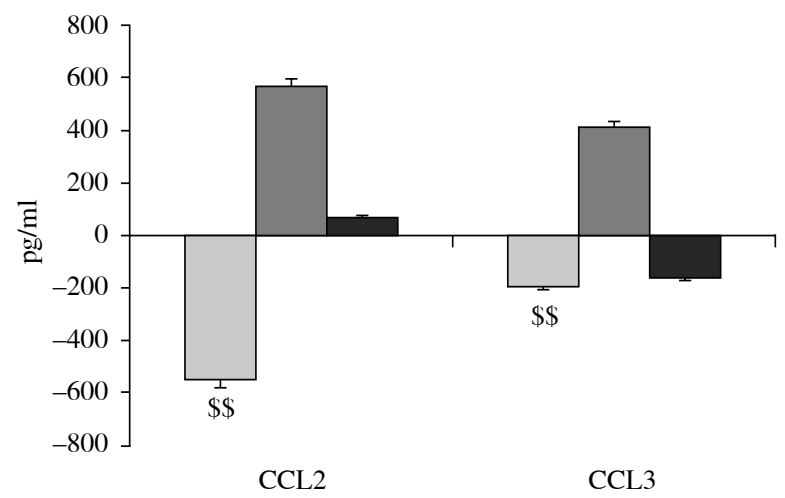

$\square$ IL-1Ra responders $\square$ IL-1Ra non-responders $\square$ placebo

Fig. 1. Mean changes in the serum concentrations of CCL2 and CCL3 from baseline in the rheumatoid patients treated with IL-1Ra or a placebo. The significance of the differences between the IL-1Ra responders and non-responders was expressed as ${ }^{\$ \$} p<0.01$.

Compared with the healthy controls.

\section{Serum CCL3 and IL-1Ra treatment}

The before- and after-treatment serum CCL3 level changes amongst the treated patients were significantly higher than those in the healthy controls $(p<0.01$ and $p<0.05$, respectively). There were no significant differences in the serum CCL3 levels and the mean CCL3 changes from baseline between the two treatment groups $(p>0.05$, Table 3$)$.
An additional comparison indicated that there were no significant differences before and after treatment amongst the IL-1Ra responders, non-responders and the placebo group $(p>0.05)$. However, a significant increase in the serum CCL3 levels was observed at the end of the study in the IL-1Ra non-responders $(p<0.05)$. The IL-1Ra responders had a higher mean change in the serum CCL3 levels from baseline than the IL-1Ra non-responders $(p<0.01$, Fig. 1).

\section{Discussion}

In our study, elevated serum CCL2 and CCL3 concentrations were found in patients with active RA, which confirm their important roles in the cell migration and aggregation during the onset and sustaining of RA synovitis $[4,11,12]$.

Klimiuk et al. [13] reported that serum expression levels of chemokines interleukin 8 (IL-8), CCL2 and CCL5 correlated with clinical activity in RA patients and declined following three months of etanercept treatment. In our study, no significant differences in the mean CCL2 and CCL3 changes from baseline at the last injection were found between the IL-1Ra and placebo treated groups. However, further comparison revealed that both mean changes of serum CCL2 and CCL3 in the IL-1Ra responders significantly decreased, as compared to IL-1Ra non-responders. Additionally, the elevated serum CCL2 levels at baseline declined to healthy levels in patients who had

Table 3. Serum CCL3 concentrations before and after treatment

\begin{tabular}{lccc}
\hline & Before treatment & After treatment & Mean changes \\
\hline IL-1Ra group & $204.7 \pm 489.0^{* *}$ & $253.9 \pm 407.3^{*}$ & $47.15 \pm 679.1$ \\
\hline IL-1Ra responders & $318.6 \pm 632.5^{*}$ & $121.2 \pm 257.6$ & $-197.4 \pm 689.0^{\text {ss }}$ \\
\hline IL-1Ra non-responders & $52.93 \pm 47.74$ & $452.9 \pm 520.1^{*}$ & $414.0 \pm 499.5$ \\
\hline Placebo group & $563.7 \pm 788.6^{* *}$ & $293.7 \pm 630.1^{*}$ & $-161.9 \pm 279.1$ \\
\hline
\end{tabular}

\begin{tabular}{ll}
\hline Healthy controls & $29.62 \pm 17.7$
\end{tabular}

The values are expressed as the mean \pm SD. CCL3 - macrophage inflammatory protein-1 $\alpha(M I P-1 \alpha)$. Compared with the healthy controls, $* p<0.05, * * p<0.01$. Compared with the IL-1Ra non-responders, ${ }^{\$ \$} p<0.01$ 
good response to 24 weeks' IL-1Ra treatment. The findings suggest that IL-1Ra therapy may lower the levels of serum CCL2 and CCL3 while also reducing disease symptoms; therefore, serum CCL2 and CCL3 may be used as efficacy markers of IL-1Ra treatment.

In conclusion, CCL2 and CCL3 may play a pivotal role in RA synovitis and may be useful efficacy markers of IL-1Ra treatment. Biologics have brought a new era for RA treatment, but the appropriate time to taper or stop drug treatment is still unclear to rheumatologists. Serum CCL2 and CCL3 may be used as markers to indicate the best time for withdrawal. However, further investigation in a larger population is needed.

Dr. J Bao performed the ELISA, the statistical analysis and drafted the manuscript. Dr. Liu performed the clinical studies and collected the data. Dr. YX Bao conceived the study, participated in its design and coordination and revised the manuscript. All of the authors read and approved the final version of the manuscript.

This study was supported in part by grants from the $\mathrm{Na}$ tional Natural Science Foundation of China (No. 81172782).

The authors declare no conflicts of interest.

\section{References}

1. St Clair EW (2002): Tides of inflammation: impact of biologics. J Rheumatol Suppl 65: 22-26.

2. Bresnihan B, Cobby M (2003): Clinical and radiological effects of IL-1Ra in patients with rheumatoid arthritis. Rheumatology (Oxford) 42 Suppl 2: ii22-ii28.

3. Nixon R, Bansback N, Brennan A (2007): The efficacy of inhibiting tumour necrosis factor $\alpha$ and interleukin 1 in patients with rheumatoid arthritis: a meta-analysis and adjusted indirect comparisons. Rheumatology 46: 1140-1147.

4. Szekanecz Z, Koch AE, Tak PP (2011): Chemokine and chemokine receptor blockade in arthritis, a prototype of immune-mediated inflammatory diseases. Neth J Med 69: 356-366.

5. Iwamoto T, Okamoto H, Toyama Y, Momohara S (2008): Molecular aspects of rheumatoid arthritis: chemokines in the joints of patients. FEBS J 275: 4448-4455.

6. Katrib A, Tak PP, Bertouch JV, et al. (2001): Expression of chemokines and matrix metalloproteinases in early rheumatoid arthritis. Rheumatology (Oxford) 40: 988-994.

7. Katrib A, Smith MD, Ahern MJ, et al. (2003): Reduced chemokine and matrix metalloproteinase expression in patients with rheumatoid arthritis achieving remission. J Rheumatol 30: 10-21.

8. Bao J, Yue T, Liu W, et al. (2011): Secondary failure to treatment with recombinant human IL-1 receptor antagonist in Chinese patients with rheumatoid arthritis. Clin Rheumatol 30: 697-701.

9. Felson DT, Anderson JJ, Boers M, et al. (1995): American College of Rheumatology. Preliminary definition of improvement in rheumatoid arthritis. Arthritis Rheum 38: 727-735.
10. van Gestel AM, Prevoo ML, van't Hof MA, et al. (1996): Development and validation of the European League Against Rheumatism response criteria for rheumatoid arthritis: comparison with the preliminary American College of Rheumatology and the World Health Organization/International League Against Rheumatism criteria. Arthritis Rheum 39: 34-40.

11. Szekanecz Z, Kim J, Koch AE (2003): Chemokines and chemokine receptors in rheumatoid arthritis. Semin Immunol 15: $15-21$.

12. Salcedo R, Ponce ML, Young HA, et al. (2000): Human endothelial cells express CCR2 and respond to MCP-1: direct role of MCP-1 in angiogenesis and tumor progression. Blood 96: 34-40.

13. Klimiuk PA, Sierakowski S, Domyslawska I, Chwiecko J (2011): Serum chemokines in patients with rheumatoid arthritis treated with etanercept. Rheumatol Int 31: 457-461. 